\title{
Infection of drone larvae (Apis mellifera) with American foulbrood*
}

\author{
Dieter BEHRENS ${ }^{\mathrm{a}}$, Eva FORSGREN ${ }^{\mathrm{b}}$, Ingemar FRIES ${ }^{\mathrm{b}}$, Robin F.A. MORITZ \\ ${ }^{a}$ Institut für Zoologie, Martin-Luther-Universität Halle-Wittenberg, Hoher Weg 4, 06099 Halle, Germany \\ ${ }^{\mathrm{b}}$ Department of Entomology, Swedish University of Agricultural Sciences, Box 7044, 75007 Uppsala, Sweden
}

Received 28 August 2006 - Revised 12 October 2006 - Accepted 23 October 2006

\begin{abstract}
In-vitro reared drone larvae of several sister queens from an Apis mellifera ligustica and a Buckfast breeding line were infected with Paenibacillus larvae (type strain ATCC 9545) causing American foulbrood (AFB). Although drone larvae were susceptible to AFB and could be infected under in-vitro conditions there were differences within and between lineages. Infection sensitivity was higher in the $A . m$. ligustica line compared to the Buckfast line. Different infection thresholds were found among sister queens of the A. $m$. ligustica line suggesting a considerable genetic variance for larval resistance against AFB.
\end{abstract}

Paenibacillus larvae / disease resistance / in-vitro rearing / mortality

\section{INTRODUCTION}

American foulbrood (AFB) is caused by the spore-forming bacterium Paenibacillus larvae (sensu Genersch et al., 2006). The spores germinate in the larval midgut of young larvae and penetrate the midgut epithelium, and finally enter the body cavity. Infection results in death of the larva and degradation of the larval tissues to a brownish sticky mass. Dead larvae are highly contagious and may contain about $2.5 \times 10^{9}$ spores (Sturtevant, 1932). Worker bees become contaminated when removing dried larvae, which probably is an important infection pathway to spread the infectious spores in the colony. Infection may also be transferred horizontally between colonies by robbing of contaminated honey or drifting of spore carrying adult bees. The spores are extremely long-lived and can germinate even after more than 35 years (Haseman, 1961), probably making nesting sites and beekeeping equipment important vectors for transmis-

Corresponding author: D. Behrens, dieter.behrens@zoologie.uni-halle.de

* Manuscript editor: Marla Spivak sion. The pathogen is often present without producing clinical disease signs visible to the beekeeper (Fries et al., 2006), but when clinical disease occur, infected colonies often succumb to the disease (Hansen and Brødsgaard, 1999). Thus, AFB is considered to be one of the most destructive brood diseases in honeybees (Burnside et al., 1949).

Although AFB was identified for more than a 100 years, it still plagues beekeeping world wide. Current strategies to fight AFB include antibiotic treatments, killing of infected colonies, large scale quarantine actions (Hansen and Brødsgaard, 1999) and breeding resistant honeybee strains.

Since the 1930's honeybee lines are known to differ in resistance to AFB at the colony level (reviewed by Rothenbuhler, 1958). Traits or conditions known to be associated with disease resistance include intensity of hygienic behaviour (reviewed by Spivak and Gilliam, 1998a, b), removal of spores from the honey by action of the honey stopper (Sturtevant and Revell, 1953) and food compounds such as fatty acids (Rose and Briggs, 1969) and pollen 
(Rinderer and Rothenbuhler, 1974) that reduce bacterial growth of $P$. larvae.

In addition, Rothenbuhler and Thompson (1956) showed that individual larvae can have an innate resistance to AFB. Palmer and Oldroyd (2003) found that workers of different patrilines within a colony differ in AFB resistance demonstrating that larval resistance has an allelic component. The finding that expression levels of antimicrobial peptides, especially abaecin, after infection with AFB differ among lineages (Evans, 2004) and that expression levels correlate with resistance at the colony level (Evans and Pettis, 2005) indicate that compounds of the immune system may play an important role in larval resistance and that larval resistance may act as a measurement for colony resistance. However, the biological mechanisms of larval resistance are not fully understood.

This study aims to detect differences in larval resistance between and within honeybee lines to test for genetic variance in larval disease resistance. We take advantage of male haploidy for testing genetic variance of AFB susceptibility among drone larvae in an exposure bioassay. Using the in-vitro rearing of larvae, we can eliminate all factors known to influence colony level AFB resistance (e.g. hygienic nurse bees, variance in infection load) and monitor larval development under highly controlled conditions.

\section{MATERIALS AND METHODS}

\subsection{Honeybee lines and queen treatment}

Seven sister queens of a Buckfast breeding line and three sister queens of an A. m. ligustica breeding line were used for this study. One week old virgin queens were gassed twice with $\mathrm{CO}_{2}$ for five minutes. This procedure initiates egg-laying and since all queens were unmated they exclusively laid unfertilized eggs developing into haploid drones.

\subsection{In-vitro-rearing}

Larvae were reared in-vitro following a protocol according to Peng et al. (1992) modified according to Genersch et al. (2005). Drone larvae were reared in 24-well tissue culture plates with a diet consisting of $66 \%$ royal jelly (v/v) (Stakich, Inc., Bloomfield Hills, MI, USA), 3\% glucose (w/v) and 3\% fructose $(\mathrm{w} / \mathrm{v})$ in sterile distilled water. The wells were filled with approximately $0.3 \mathrm{~mL}$ of this diet using a scaled sterile syringe. Larvae younger than 24 hours were taken from the combs using a Chinese grafting tool (Graze Bienenzuchtgeräte, Germany) and carefully transferred to the surface of infectious larval diet. Larval age was estimated by size. After 24 hours the growing larvae were transferred to a new well with uninfected diet. Dead larvae were removed. On subsequent days the larvae were transferred to fresh diet every second day to reduce handling stress. Due to larval growth the number of larvae per well was ten, five, three and one at the first, second, forth, and sixth day respectively. For larger larvae a rounded sterile metal hook was used to transfer the larvae from one well to the other.

The larvae were maintained in an incubator at $35^{\circ} \mathrm{C}$ with a relative humidity of $96 \%$.

Experiments were terminated at day nine when drone larvae reached the prepupal stage because only little additional mortality after day nine was observed in a first set of five pilot experiments which were run up to 14 days.

\subsection{Infection and bacterial isolates}

The P. larvae, ERIC I genotype (Genersch et al., 2006), type strain ATCC 9545 from the American Type Culture Collection was used for all infection experiments. This strain has a comparatively low individual larval virulence in the sense of killing its host slowly (Genersch et al., 2005). Using this particular strain, we expected larger variance in mortality, thus allowing a higher resolution of detecting temporal differences in the reaction of honeybee lines to the pathogen.

The concentration of the spore stock solution was estimated by viable cell counting. A defined volume of spore solution was spread onto MYPGPagar plates in 5 replicates. Plates were placed in an incubator $\left(35{ }^{\circ} \mathrm{C}, 96 \%\right.$ humidity, $\left.5 \% \mathrm{CO}_{2}\right)$ for ten days and colonies were counted (Nordström and Fries, 1995).

The concentration of the stock solution was adjusted to approximately 20.000 colony forming units (cfu) per $\mathrm{mL}$. Since the number of colonies 


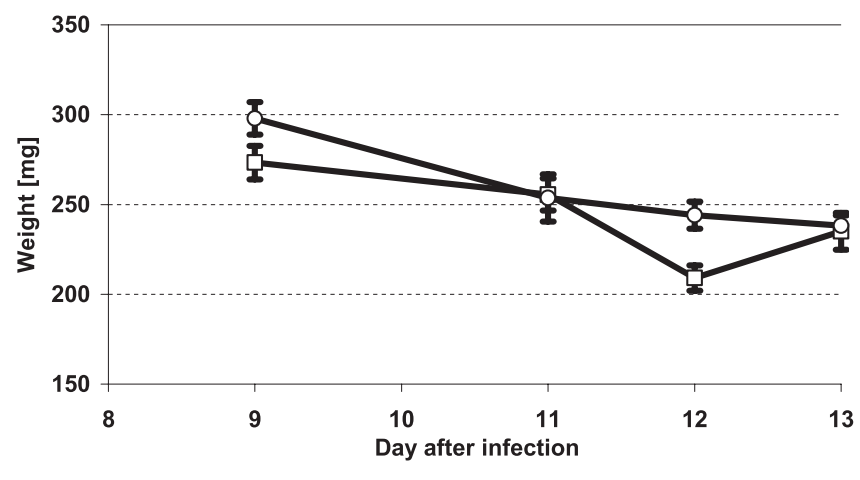

Figure 1. Average weight $(\mathrm{mg} \pm$ s.e.) of surviving infected (open circles, $\mathrm{n}=326)$ and control larvae (open squares, $\mathrm{n}=286$ ). obtained in a viable count depends on a number of factors (e.g. suitability of culture medium, incubation conditions), underestimation of the actual viable cell mass within infected larvae is highly likely. Spore suspensions were stored at $4{ }^{\circ} \mathrm{C}$.

For infection of the larvae the spore solution was thoroughly vortexed and mixed with the larval diet using a syringe to distribute the spores evenly. Larvae of the treatment group were placed on $0.3 \mathrm{~mL}$ of infectious diet with the defined spore concentration for $24 \mathrm{~h}$. At subsequent days all larvae were fed normal diet. Control larvae were fed normal diet throughout the experiment.

\subsection{Measuring mortality}

Control and infected larvae were observed every 24 hours under a stereo microscope. Dead larvae were identified by ceased respiration, displayed colour change and body surface reflecting light differently due to dehydration. These combined traits made it easy to identify dead larvae. Dead larvae were removed from the experiment, weighed and frozen for future genetic analysis. At the end of the experiments all survivors were recorded, weighed and frozen. Larvae that died in the first 24 hours were excluded from the analyses because mortality due to infection of $P$. larvae never occurs before the second day post infection (Genersch et al., 2005).

Control and treatment group were checked for significant differences by making a survival analysis with Gehan's Wilcoxon test. This is a standard test to compare survival in two or more groups with censored observations (Gehan, 1969).

\section{RESULTS}

\subsection{Larval weight}

Figure 1 shows the effect of infection on larval body weight of larvae that survived the experiment. The differences in larval development between controls and treatment were not statistically significant (hierarchical nested ANOVA, days nested into treatment, $P=$ 0.666). Furthermore, no obvious impact of infection on larval development was observed. $70 \%$ of the surviving larvae reached prepupal stage on day nine (100\% on day 10$)$ after infection irrespective of treatment.

\subsection{Dose-mortality relationship}

The mortality of drone larvae from one A. m. ligustica queen was tested with two different spore concentrations (Fig. 2). There were no significant difference between the control and the treatment group at the concentration of $400 \mathrm{cfu} / \mathrm{mL}$ (Gehan's Wilcoxon test, $P=0.191)$. In the treatment group with $1000 \mathrm{cfu} / \mathrm{mL}$, however, mortality differed significantly from the control group and the group given the lower spore dose (Gehan's Wilcoxon test, $P<0.001$ ).

\subsection{Differences between lines}

We compared the two honeybee lines, by calculating the difference between mean mortality in control and treatment group per queen 

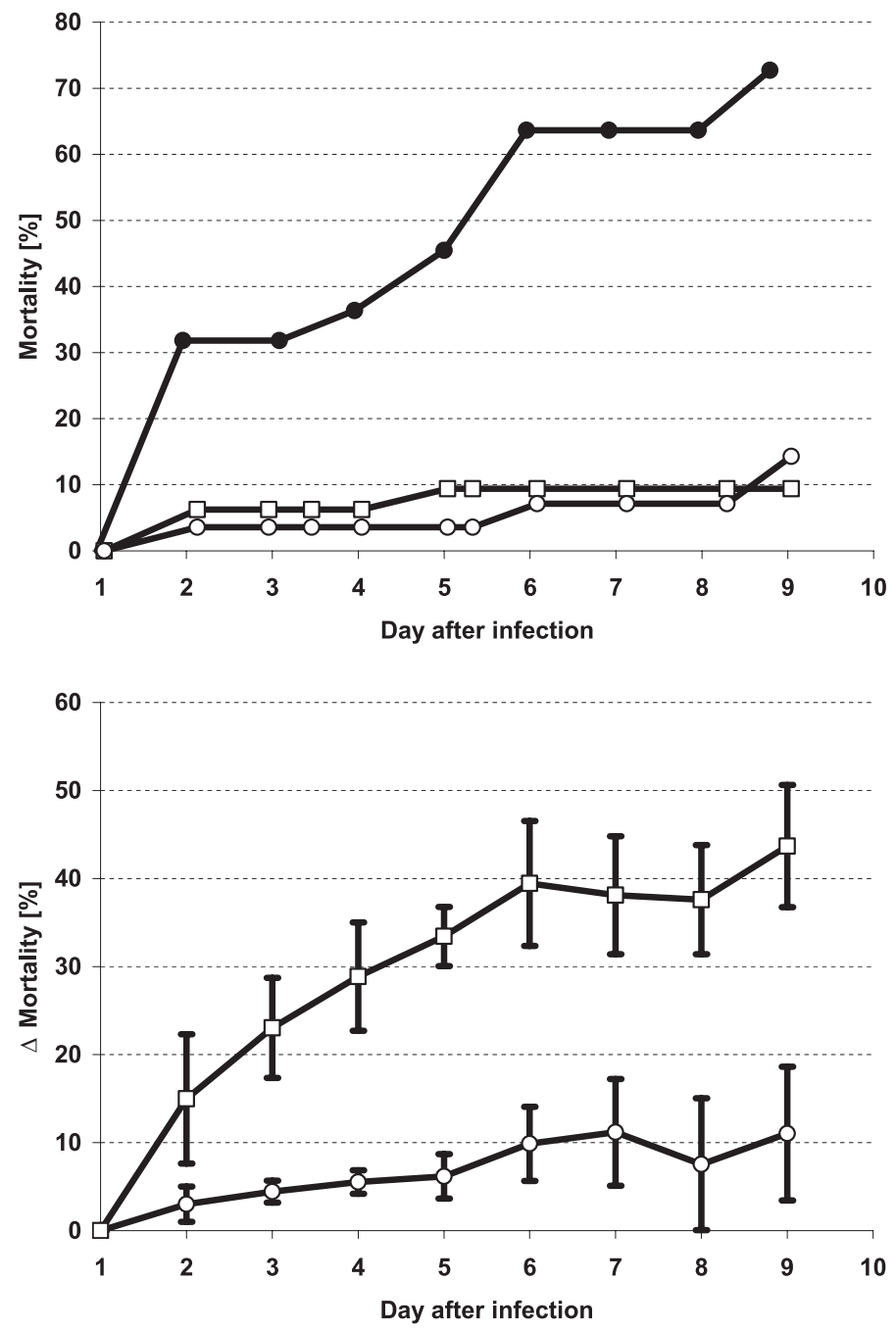

Figure 2. Dose-mortality effect. Average cumulative mortality (\%) of A. m. ligustica drone larvae infected with 400 (open circles, $\mathrm{n}=28$ ) and $1000 \mathrm{cfu} / \mathrm{mL}$ (filled circles, $\mathrm{n}=$ 22). Untreated controls; open squares, $\mathrm{n}=32$.

Figure 3. Average mortality (\% corrected for control) of drone larvae of the Buckfast (open circles, $\mathrm{n}=102$ ) and the A. $m$. ligustica line, treated with $1000 \mathrm{cfu} / \mathrm{mL}$ (open squares, $\mathrm{n}=$ 125).

for all three A. m. ligustica sister queens and all seven Buckfast sister queens at a spore concentration of $1000 \mathrm{cfu} / \mathrm{mL}$ (Fig. 3). The survival analysis showed a significant difference between the treatment groups (Gehan's Wilcoxon test, $P=0.033, \mathrm{n}=102$ Buckfast and $125 \mathrm{~A}$. m. ligustica drone larvae).

In the Buckfast line infection with a concentration of $400 \mathrm{cfu} / \mathrm{mL}$ did not result in an increased mortality compared to the control group up to day nine (Gehan's Wilcoxon test, $P=0.460, \mathrm{n}=230$ controls and 176 infected) but differences were highly significant at the higher concentration of $1000 \mathrm{cfu} / \mathrm{mL}$ (Gehan's
Wilcoxon test, $P=0.009, \mathrm{n}=230$ controls and 128 infected).

In the A. m. ligustica line infection resulted in an increased mortality at both concentrations, $400 \mathrm{cfu} / \mathrm{mL}$ (Gehan's Wilcoxon test, $P=0.040, \mathrm{n}=272$ controls and 59 infected) and $1000 \mathrm{cfu} / \mathrm{mL}$ (Gehan's Wilcoxon test, $P<0.001, \mathrm{n}=272$ controls and 140 infected). The standard errors in the treatment group were high, indicating a strong variance among queens within the $A$. m. ligustica line.

Absolute values for the mean mortality in the treatment group were higher in the A. $m$. ligustica line at both concentrations $(37.8 \%$ 
respectively $59.3 \%$ at day nine after infection) than in the Buckfast line (27.1\% respectively $40.9 \%)$.

\subsection{Differences within lines}

Within the A. $m$. ligustica line differences in mortality between controls and treatment were not significant for $A$. $m$. ligustica queen A at the concentration of $400 \mathrm{cfu} / \mathrm{mL}$ (Gehan's Wilcoxon test, $P=0.191$ ) but highly significant for the concentration of $1000 \mathrm{cfu} / \mathrm{mL}$ (Gehan's Wilcoxon test, $P<0.001$ ) as well as between the two treatment groups (Gehan's Wilcoxon test, $P<0.001$ ) (Fig. 4). Differences in mortality were highly significant for A. $m$. ligustica sister queen B at both concentrations $400 \mathrm{cfu} / \mathrm{mL}$ (Gehan's Wilcoxon test, $P<0.001$ ) and $1000 \mathrm{cfu} / \mathrm{mL}$ (Gehan's Wilcoxon test, $P<0.001)$. Differences were highly significant in $A$. $m$. ligustica queen $\mathrm{C}$ even for the concentration of $200 \mathrm{cfu} / \mathrm{mL}$ (Gehan's Wilcoxon test, $P=0.004$ ) as well as for $1000 \mathrm{cfu} / \mathrm{mL}$ (Gehan's Wilcoxon test, $P<0.001)$.

While all three progeny sets from the A. m. ligustica line were susceptible at a dose of $1000 \mathrm{cfu} / \mathrm{mL}$ only one of seven sets from the Buckfast line was equably susceptible (Gehan's Wilcoxon test, $P=0.048$ at $400 \mathrm{cfu} / \mathrm{mL}$ and $P=0.024$ at $1000 \mathrm{cfu} / \mathrm{mL}$ ). The absolute values for the mortality in the treatment group at day nine after infection were $24.2 \%$ at $400 \mathrm{cfu} / \mathrm{mL}$ and $27.3 \%$ at $1000 \mathrm{cfu} / \mathrm{mL}$.

\section{DISCUSSION}

\subsection{Larval weight}

The weight of surviving drone larvae in both treatment and controls match the values given in the literature for drone larvae reared under natural conditions (reviewed by Jay, 1963). This suggests that the in-vitro-rearing conditions per se have no negative impact on larval development.

\subsection{Infection of drones}

We could show that in-vitro rearing is a feasible routine method to study susceptibility of drone larvae to AFB under controlled conditions. Drone larvae were found to be clearly susceptible to AFB in this exposure bioassay confirming the observations of Woodrow and Holst (1942) that not only workers but also drone and queen larvae can become infected. Genersch et al. (2005) estimated a $\mathrm{LC}_{50}$ (concentration that is lethal for $50 \%$ of the infected larvae) of $200 \mathrm{cfu} / \mathrm{mL}$ for the strain ATCC 9545 with in-vitro reared worker larvae. The $\mathrm{LC}_{50}$ of all drone larvae used in this study would be five times higher around $1000 \mathrm{cfu} / \mathrm{mL}$. At this concentration 128 out of 266 treated drone larvae died before day nine, which represents a mortality of $48.1 \%$ (disregarding control mortality). In our exposure bioassays the concentration of bacterial stock solution was determined by colony count on MYPGP agar and incubation with $5 \% \mathrm{CO}_{2}$, whereas Genersch et al. (2006) used Columbia sheep blood agar without carbon dioxide. Nordström and Fries (1995) demonstrated that MYPGP agar and a $5 \% \mathrm{CO}_{2}$ atmosphere enhances spore growth about five times compared to Blood agar without $\mathrm{CO}_{2}$. Hence, the spore dose resulting in a $50 \%$ mortality of drone larvae may in fact be coherent with the lethal dose suggested by Genersch et al. (2006) for this bacterial strain in worker larvae.

Nevertheless, it is possible that drone larvae respond differently to infection with AFB than worker larvae due to developmental differences, for example a different time span between moultings. Further studies on larval resistance to AFB should include comparisons between drone and worker larvae.

\subsection{Variation between and within lines}

The progeny of queens from the Buckfast line was found to be less susceptible to the tested spore concentrations than the $A$. $m$. ligustica line. This confirms that honeybee lines do vary in their susceptibility to AFB infection at the larval level. The differences among the drone offspring of the three A. $\mathrm{m}$. 


\section{A. m. ligustica sister queen A}

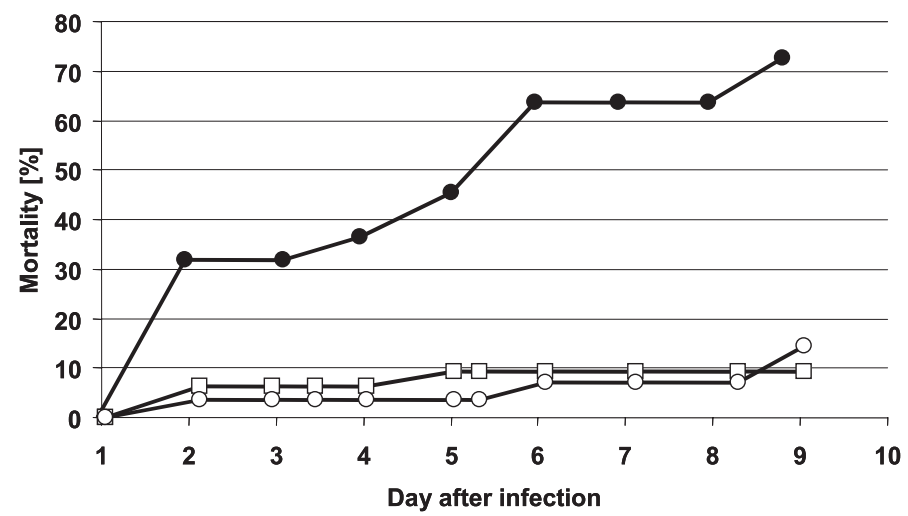

$\rightarrow \square-$ control (32) $-\mathrm{O}-400 \mathrm{cfu} / \mathrm{mL}(28)-1000 \mathrm{cfu} / \mathrm{mL}(22)$

\section{A. m. ligustica sister queen B}

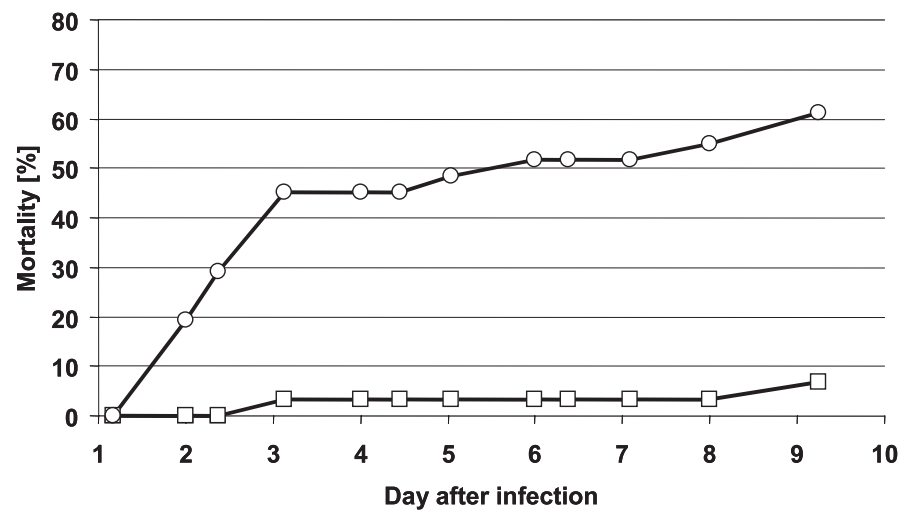

$\neg \square-$ control (30) $-0-400 \mathrm{cfu} / \mathrm{mL}$ (31)

A. m. ligustica sister queen C

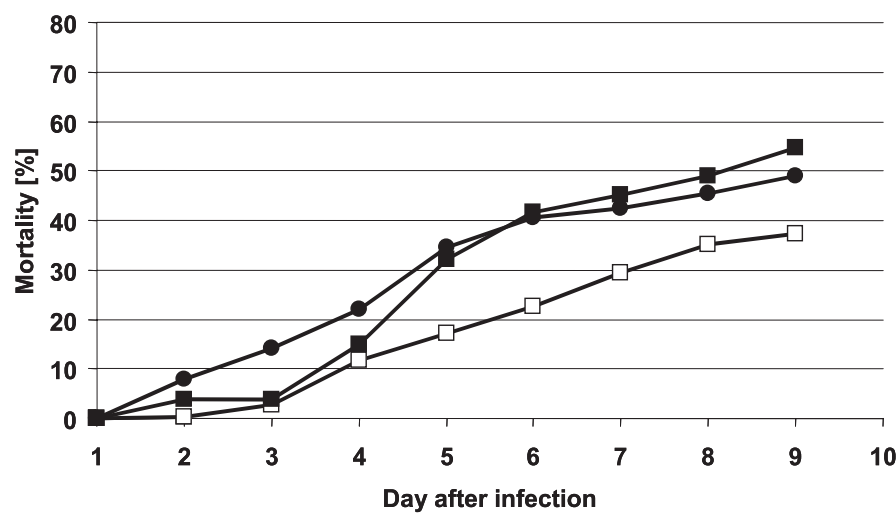

control (202) +/- SE
Figure 4. Average mortality (\% corrected for controls) of drone larvae of the three $A . m$. ligustica sister queens (A, B and C) and treatment groups with 200 (filled squares), 400 (open circles) and $1000 \mathrm{cfu} / \mathrm{mL}$ (filled circles). Numbers in parenthesis indicate sample sizes. 
ligustica queens suggest a genetic variance for a susceptibility threshold, below which infection is sublethal up to day nine after infection. This threshold seems to lie between 400 and $1000 \mathrm{cfu} / \mathrm{mL}$ for queen $\mathrm{A}$, below $200 \mathrm{cfu} / \mathrm{mL}$ for queen $\mathrm{B}$ and probably above $1000 \mathrm{cfu} / \mathrm{mL}$ for queen $\mathrm{C}$, although high control mortality makes interpretations difficult. We expect that susceptibility thresholds of the tested Buckfast queens were all above our tested concentrations.

We used only one bacterial strain for infections. Given the found differences in pathogen virulence among AFB strains (Genersch et al., 2005) it is possible that other strains would lead to different results, that certain strains are adapted to certain bee lines or that different bacterial strains differ in pathogenicity between bee lines as suggested by Fries and Camazine (2001). Considering the low number of queens we used and their close relatedness, we can not say, whether Buckfast bees in general are more resistant to AFB compared to Italian bees.

Different levels of antimicrobial peptides, as found by Evans and Pettis (2005), might have led to the observed variance. In our study larvae received food ad libitum. Thus, it is not possible to say, whether resistance had an energetic cost leading to reduced colony productivity, if larvae compensate infection by additional feeding. To understand if larval resistance to AFB has an energetic cost it would be necessary to restrict or measure the amount of diet consumed by the larvae.

Future work will aim at identifying the genes responsible for the observed variance in disease resistance and to investigate their role in the resistance mechanism.

\section{ACKNOWLEDGEMENTS}

The authors thank Hans-Heinrich Kaatz for technical support and advice and the EU network BEESHOP for funding.

Infection par la loque américaine des larves de mâles de deux lignées d'abeilles domestiques (Apis mellifera).
Paenibacillus larvae / résistance à la maladie / mortalité / élevage in-vitro

Zusammenfassung - Infektion von Drohnenlarven (Apis mellifera) mit Amerikanischer Faulbrut. Drohnenlarven von Schwesterköniginnen einer Buckfast und einer Apis mellifera ligustica Brutlinie wurden mit Sporen eines BakterienTypstammes von Paenibacillus larvae, dem Erreger der Amerikanischen Faulbrut (AFB), einer schweren Brutkrankheit der Honigbiene, infiziert. Die Sterblichkeit der Larven wurde täglich in nichtinfizierten Kontrollen und der sporenbehandelten Gruppe aufgenommen. Die Larven wurden unter kontrollierten in-vitro Bedingungen aufgezogen, um alle Faktoren auszuschließen, die bekanntermaßen AFB Resistenz auf Kolonieebene beeinflussen (z.B. hygienisches Verhalten, Futterkomponenten). Larven der untersuchten Königinnen der Buckfastlinie waren bei den untersuchten Sporendosen weniger anfällig als Nachkommen der Apis mellifera ligustica Linie (Abb. 1). Dies zeigt, dass in verschiedenen Honigbienenlinien unterschiedliche Resistenzniveaus existieren. Wir können allerdings nicht sagen, ob die gefundenen Resistenzniveaus repräsentativ für alle Buckfast bzw. Apis mellifera ligustica Linien sind und ob sie auch konsistent für andere Bakterienstämme wären. Innerhalb der $A$. $m$. ligustica Linie fanden wir eine Varianz für Infektionsgrenzwerte (Abb. 2). Dies zeigt, dass diese Grenzwerte auch genetisch beeinflusst sein können. Zusätzlich wurde eine Methode entwickelt, um Varianz in larvaler Resistenz gegen AFB zu bestimmen, unter Benutzung haploider Drohnenlarven.

Paenibacillus larvae / Krankheitsresistenz / in-vitro Aufzucht / Sterblichkeit

\section{REFERENCES}

Burnside C.E., Sturtevant A.P., Holst E.C. (1949) Diagnosing bee diseases in the apiary, US Dept. Agric. Circ. 392, 31 p.

Evans J.D. (2004) Transcriptional immune responses by honey bee larvae during invasion by the bacterial pathogen, Paenibacillus larvae, J. Invertebr. Pathol. 85, 105-111.

Evans J.D., Pettis J.S. (2005) Colony-level impacts of immune responsiveness in honey bees, Apis mellifera, Evolution 59, 2270-2274.

Fries I., Camazine S. (2001) Implications of horizontal and vertical pathogen transmission for honey bee epidemiology, Apidologie 32, 199-214.

Fries I., Lindström A., Korpela S. (2006) Vertical transmission of American foulbrood 
(Paenibacillus larvae) in honey bees (Apis mellifera), Vet. Microbiol. 114, 269-274.

Gehan E.A. (1969) Estimating survival functions from the life table, J. Chronic Dis. 21, 629-644.

Genersch E., Ashiralieva A., Fries I. (2005) Strainand genotype-specific differences in virulence of Paenibacillus larvae subsp. larvae, a bacterial pathogen causing American foulbrood disease in honeybees, Appl. Environ. Microbiol. 71, 7551-7555.

Genersch E., Forsgren E., Pentikainen J., Ashiralieva A., Rauch S., Kilwinski J., Fries I. (2006) Reclassification of Paenibacillus larvae subsp. pulvifaciens and Paenibacillus larvae subsp. larvae as Paenibacillus larvae without subspecies differentiation, Int. J. Syst. Evol. Microbiol. 56, 501-511.

Hansen H., Brødsgaard C.J. (1999) American foulbrood: a review of its biology, diagnosis and control, Bee World 80, 5-23.

Haseman L. (1961) How long can spores of American foulbrood live? Am. Bee J. 101, 298-299.

Jay S.C. (1963) The development of honeybees in their cells, J. Apic. Res. 2, 117-134.

Nordström S., Fries I. (1995) A comparison of media and cultural conditions for identification of Bacillus larvae in honey, J. Apic. Res. 34, 97-103.

Palmer K.A., Oldroyd B.P. (2003) Evidence for intra-colonial genetic variance in resistance to American foulbrood of honey bees (Apis mellifera): further support for the parasite/pathogen hypothesis for the evolution of polyandry, Naturwissenschaften 90, 265-268.

Peng Y.S.C., Mussen E., Fong A., Montague M.A., Tyler T. (1992) Effects of chlortetracycline of honeybee worker larvae reared in vitro, J. Invertebr. Pathol. 60, 127-133.

Rinderer T.E., Rothenbuhler W.C. (1974) The influence of pollen on the susceptibility of honey-bee larvae to Bacillus larvae, J. Invertebr. Pathol. 23, 347-350.

Rose R.I., Briggs J.D. (1969) Resistance to American foulbrood in honeybees. IX. Effects of honeybee larval food on the growth and viability of Bacillus larvae, J. Invertebr. Pathol. 13, 74-80.

Rothenbuhler W.C. (1958) Genetics and breeding of honeybee, Annu. Rev. Entomol. 3, 161-180.

Rothenbuhler W.C., Thompson V.C. (1956) Resistance to American foulbrood in honeybees. I. Differential survival of larvae of different genetic lines, J. Econ. Entomol. 49, 470-475.

Spivak M., Gilliam M. (1998a) Hygienic behaviour of honeybees and its application for control of brood diseases and varroa. Part I. Hygienic behaviour and resistance to American foulbrood, Bee World 79, 124-134.

Spivak M., Gilliam M. (1998b) Hygienic behaviour of honeybees and its application for control of brood diseases and varroa. Part II. Studies on hygienic behaviour since the Rothenbuhler era, Bee World 79, 169-186.

Sturtevant A.P. (1932) Relation of commercial honey to the spread of American foulbrood, J. Agric. Res. 45, 257-285.

Sturtevant A.P., Revell I.L. (1953) Reduction of Bacillus larvae spores in liquid food of honeybees by action of the honey stopper, and its relation to the development of American foulbrood, J. Econ. Entomol. 46, 855-860.

Woodrow A.W., Holst E.C. (1942) The mechanism of colony resistance to American foulbrood, J. Econ. Entomol. 35, 327-330. 